\title{
HeLa Cells Containing a Truncated Form of DNA Polymerase Beta are More Sensitized to Alkylating Agents than to Agents Inducing Oxidative Stress
}

\author{
Kalyani Khanra ${ }^{1}$ Anindita Chakraborty ${ }^{2}$, Nandan Bhattacharyya ${ }^{1 *}$
}

\begin{abstract}
The present study was aimed at determining the effects of alkylating and oxidative stress inducing agents on a newly identified variant of DNA polymerase beta (pol $\beta \Delta 208-304)$ specific for ovarian cancer. Pol $\beta \Delta 208-304$ has a deletion of exons 11-13 which lie in the catalytic part of enzyme. We compared the effect of these chemicals on HeLa cells and HeLa cells stably transfected with this variant cloned into in pcDNAI/neo vector by MTT, colony forming and apoptosis assays. Pol $\beta \Delta_{208-304}$ cells exhibited greater sensitivity to an alkylating agent and less sensitivity towards $\mathrm{H}_{2} \mathrm{O}_{2}$ and $\mathrm{UV}$ when compared with HeLa cells alone. It has been shown that cell death in Pol $\beta \Delta_{208-304}$ transfected HeLa cells is mediated by the caspase 9 cascade. Exon 11 has nucleotidyl selection activity, while exons 12 and 13 have dNTP selection activity. Hence deletion of this part may affect polymerizing activity although single strand binding and double strand binding activity may remain same. The lack of this part may adversely affect catalytic activity of DNA polymerase beta so that the variant may act as a dominant negative mutant. This would represent clinical significance if translated into a clinical setting because resistance to radiation or chemotherapy during the relapse of the disease could be potentially overcome by this approach.
\end{abstract}

Keywords: Mutation - DNA polymerase beta - base excision repair - apoptosis - caspase

Asian Pac J Cancer Prev, 16 (18), 8177-8186

\section{Introduction}

Human body is being exposed to different kinds of carcinogens, radiation every day. These constant bombardments are causing the DNA damage both in the nucleus and in the mitochondria. In order to manage these high frequencies of DNA damage, nature has developed different DNA repair mechanisms that can be run in parallel to repair the DNA. Base Excision Repair (BER) pathway is one of these pathways, that highly involves the repair of alkylating agent mediated DNA damage by single nucleotide repair pathway (short-patch repair pathway) and the other 2-8 nt repair pathway or long patch repair pathway (Sobol et al., 1996; Fortini et al., 2003; Slupphaug et al., 2003).

The loss of BER activity due to the inefficient function of any of these BER proteins may lead to or further contributes to the development of cancer, neurodegenerative disorders; etc (Singhal e al., 1995; Wilson et al., 2000; Idris et al., 2002). In order to repair efficiently, the activities of BER proteins are tightly regulated. DNA polymerase $\beta$ is the smallest enzyme in BER pathway. It belongs to the $\mathrm{X}$ family of polymerase (Wilson et al., 2000). It is a single copy $34 \mathrm{~kb}$ gene consisting of 14 exons (Sobol et al., 1996). It is located in chromosome no 8p12 (Beard and Wilson, 2006). DNA Pol $\beta$ encodes a $39 \mathrm{kDa}$ protein consisting of 335 amino acids with two subunits, small subunit of $8 \mathrm{kDa}$ (1 amino acids residues to 87 amino acids) and large subunit of $31 \mathrm{kDa}$ (88 amino acids residues to 335 amino acids) connected by a protease sensitive hinge region (Beard \& Wilson, 2000). The catalytic property of DNA polymerase $\beta$ resides in the Carboxyl terminal region of the $31 \mathrm{kDa}$ domain, whereas the amino terminal $8 \mathrm{kDa}$ domain shows a single strand DNA binding activity. This small subunit have single strand DNA binding activity and dRP lyase activity encoded by exons I-IV, its activity is necessary to direct Pol $\beta$ to short gaps possessing a 5'-phosphate termini (Wilson et al., 2000; Sobol and Wilson, 2001). The large subunit has double strand DNA binding activity and catalytic activity.

DNA polymerase beta is linked to cancer which was detected in different cell lines and tumor tissue sample of cancer (Bhattacharyya et al., 1999a; Bhattacharyya et al., 1999b; Chen et al., 2000; Bhattacharyya et al., 2001; Chen et al., 2002; Khanra et al., 2012a, 2012b, 2012d). It was claimed that $30 \%$ cases of cancer polymerase beta have mutation (Starcevic et al., 2004; Lang et al., 2007). In gastric cancer patients out of 20 samples $6(30 \%)$ have pol beta mutation (Iwanaga et al., 1999). In colorectal cancer 
6 in 8 patients $(75 \%)$ have polymerase beta mutation (Lang et al., 2004). In breast cancer, 26\%, esophageal cancer, $40 \%$ have mutation (Dong et al., 2002). Almost $36 \%$ tumors express polymerase beta variant in which deletion of exon 11 is highly common. This variant of polymerase beta is expressed in colorectal, breast, lungs adenocarcinomas (Sweasy et al., 2005). In colorectal cancer K289M (Sweasy et al., 2005) was detected which has less BER activity. Expression of cancer-associated pol $\beta$ variants in mouse cells could lead to a series of cancer associated phenotypes, including an increased mutation frequency and the induction of cellular transformation (Sweasy et al., 2005). The gastric cancer associated variant E295K has a phenotype that could be related with etiology of cancer (Lang et al., 2007). This variant is unable to catalyze DNA synthesis but have DNA binding and dRP lyase activity same as wild type (WT) pol $\beta$ (Lang et al., 2007).

Lang et al (2007) experimentally showed that this mutant when expressed in MEFs, conferred a dominantnegative phenotype and sensitivity to MMS, induced more sister chromatid exchanges (SECs) per nucleus than Wild type (WT) and it causes cellular transformation that could lead to tumorigenesis or tumor progression (Lang et al., 2004). Another Gastric cancer associated variant Leu22Pro (L22P) exhibits little dRP lyase activity but retain its polymerase activity. In 22 residues of DNA pol $\beta$ has no direct contact with the DNA, L22P variant has reduced DNA binding affinity. The L22P variant protein is deficient in base excision repair (Dalal et al., 2008). In another Gastric cancer variant (cys239arg), cys 239 is located in inflexible loop region that when altered reduced the accuracy of DNA synthesis Dobashi et al., 1994. In prostate cancer, I260M variant is located in hinge region of polymerase beta (Dalal et al., 2005). Ile260 is a key residue of the hydrophobic hinge. This hinge influences the geometry of the DNA within the polymerase active site that is important for accurate DNA synthesis and important for the closing of the polymerase and important for conformation change after substrate binding and fidelity of protein, results inaccurate DNA synthesis when replaced by Methionine. Characterization of the I260M variant shows that it has a functional phenotype that could be linked to the etiology or malignant progression of human cancer (Dalal et al., 2005). Another DNA pol $\beta$ variant $\mathrm{D} 246 \mathrm{~V}$ has been reported which is less efficient than WT for incorporation of AZT in a recessed primer template (Kosa et al., 1999). This Asp residues at position 246 helps to maintain the proper positioning of the DNA within the active site of DNA pol $\beta$. Valine at the tip of the loop results in mis-incorporation resulting from an altered or misaligned DNA structure within the active site (Kosa et al., 1999; Dalal et al., 2004). Bhattacharyya et al (1999) reported three variant of pol $\beta$ in squamous, non-small or large cell carcinomas. The common variant was large deletion of 87 bp of exon 11 which lies in catalytic part of polymerase beta. Another variant of $140 \mathrm{bp}$ deletion along with addition of exon alpha was detected. Functional study of 87 bp deleted DNA pol $\beta$ shows that it acts as dominant negative manner. This variant is unable to bind properly to double strand DNA and has lost repair activity
(Bhattacharyya et al., 1997; Bhattacharyya et al., 2000) thus acts as a dominant negative manner. In addition, when this variant is expressed in Mouse Embryonic fibroblast (MEFs) cell line, which induced tumor occurrence in nude mice (Sweasy et al., 2005). So above evidence indicate that Pol $\beta$ variants are linked to etiology of cancer.

Genomic stability is disrupted by environmental carcinogen as well as metabolically produced oxidative stress, metabolic by-product, errors during DNA replication and DNA recombination contribute to the mutations. It is estimated that BER repairs 104 lesions per cell per day and this proofreading is vital to avoid genomic instability (Lindahl, 1993; Yamtich and Sweasy, 2010). By and large, under normal circumstances, this immense error burden is successfully dealt with by the highly coordinated cellular DNA repair mechanisms thus maintaining genomic integrity.

Alkylating agents are mono-functional or bi-functional (two reactive groups) carcinogen that are able to form intra-chain and inter-chain cross-links on DNA directly. Nucleotides can be alkylated at several different positions in nitrogen and oxygen and it's biological consequences are diverse (Friedbarg EC 2003). MMS, NMU are mono alkylating agent directly incorporated in DNA. MMS is an SN2 alkylating agent that interacts with nucleophilic centers forms 7-methylguanine and 3'-methyladenine adducts in DNA (Hoffman \& Hecht 1985; Gu et al., 2010). NMU add methyl group to DNA. Endogenous alkylating agent O6-meG interferes base pairing and cause $\mathrm{G}: \mathrm{C}$ to $\mathrm{A}: \mathrm{T}$ transition mutations. Other endogenous alkylating agents 7-methylguanines (7meG) are unstable and spontaneously degrade to AP sites create single strand break (Ochs et al., 1999; Oshima et al., 2003). It was detected that Pol $\beta$ knockout cell lines are highly sensitive to methylating agents.

A UV (100-400 $\mathrm{nm}$ ) ray is a strong mutagenic agent which creates various lesions. UV A $(320-400 \mathrm{~nm})$ is mutagenic consists mostly of single strand breaks in DNA (Mouret et al., 2006; Kong et al., 2009). UVB (295-320 $\mathrm{nm}$ ) is involved in direct formation of thymine dimer or other pyrimidine dimer double strand DNA breaks. UV-C (100-295 nm), can generate hydroxyl $(\bullet \mathrm{OH})$ and oxygen radicals $(\bullet \mathrm{O} 2), \bullet \mathrm{OH}$ mainly attacks DNA integrity by removing hydrogen from the deoxyribose backbone or addition of double bonds to DNA bases or resulting base modification including multitude of altered bases, base loss, and strand breaks. The most common lesions created by UV are cyclobutane pyrimidine dimer (CPDs) and Pyrimidine-pyrimidine (6-4) photoproducts (6,4-PP) at the adjacent pyrimidine. The formation of a pyrimidine dimer causes a bend in the DNA helix and DNA polymerase cannot read the DNA template as a result DNA replication is prevented by these pyrimidine dimer, which leads to mutation. The formation of a pyrimidione (6-4) photoproduct mimics an abasic site (Douki et al., 2003).

In our lab we have reported some point mutations in the genomic DNA of ovarian tumor samples (Khanra et al., 2012a,bc). These mutations were detected at exon intron junction region of exon 8, exon 9 and exon 11 by SSCP analysis (Khanra et al., 2012c). We also have detected cDNA mutation in these samples by RT-PCR 
and Western blot analysis (Khanra et al., 2012d). One of the cDNA mutations have deletion of exon 11-13 which lies in catalytic part of DNA polymerase beta. Exon 11 consists of 29 amino acids in the region of 208-236, Exon 12 consists of 21 amino acids in the region of $237-258$, exon 13 is 45 amino acids which resides within amino acid residues 259-304.

In this report, the functional consequence of the loss of three exons of pol $\beta$ in response to alkylating agents such as Methyl methanesulfonate (MMS) and N-methyl-Nnitrosoureaa (NMU) and oxidative stress inducing agents such as UV \& $\mathrm{H}_{2} \mathrm{O}_{2}$ have been studied. The present variant of pol $\beta$ detected in ovarian cancer (Khanra et al., 2012d) has lost exon 11-13 that catalytic part is responsible for dNTP selection, nucleotidyl transferase activity and it would be interesting to determine the function of this mutant in response to alkylating agent, UV and oxidative agents.

\section{Materials and Methods}

\section{Cloning of truncated form of DNA polymerase beta in} PCDNAIneo vector

Pol $\beta \Delta 208-304$ cDNA was amplified from tumor RNA sample using primers of full length pol $\beta$ cDNA (Khanra et al., 2012d) and cloned in a vector pcDNAIneo (Invitrogen). The orientation and sequence of the mutated product was confirmed by sequencing before transecting vector $\mathrm{pcDNAI} / \mathrm{neo}$ in HeLa cell line.

\section{Transfection of Pol $\beta \Delta_{208-304}$ in HeLa cell line and stable cell line preparation}

HeLa cells were cultured in DMEM medium with $10 \%$ fetal calf serum (Gibco; USA) and $100 \mathrm{U} / \mathrm{mL}$ penicillin and $100 \mathrm{U} / \mathrm{mL}$ streptomycin at $37^{\circ} \mathrm{C}$ in a humidified atmosphere with $5 \% \mathrm{CO}_{2}$ in an incubator (SANYO, Japan). Cells were transfected by calcium phosphate coprecipitation method and Transfected cells were selected in G418 containing medium $100 \mu \mathrm{g} / \mu \mathrm{l}$.

RT-PCR analysis for expression of truncated from of Pol $\beta$ RNAs were isolated from Pol $\beta \Delta_{208-304}$ transfected cell line, HeLa cell line and only vector transfected cell line without Pol $\beta \Delta_{208-304}$ and RT-PCR was done to detect the expression of $\operatorname{Pol} \beta \Delta_{208-304}$ in transcriptional level. As per manufacturers' instruction RNAs were isolated using RNA isolation kit (Trisure, Bioline). To eliminate the possibility of genomic DNA contamination, reaction was also set up without reversed transcriptase enzyme

Western blot analysis for detecting expression of truncated DNA polymerase beta

After preparing stable cell line, cell lysates were made and western blot (Bhattacharyya et al., 2001) was done to confirm transfection of $\operatorname{Pol} \beta \Delta_{208-304}$ in cell line. Total cell lysates were isolated from transfected cell lines and control cell lines by using lysis buffer containing $10 \mathrm{mM}$ Tris- $\mathrm{HCl}$ (PH 8), 1mM EDTA, 400mM NaCl, $2 \mathrm{mM}$ beta mercaptoethanol, freshly prepared $1 \mathrm{mM}$ PMSF, and protease inhibitors (Roche applied Science). Proteins were denatured in $900 \mathrm{C}$ with SDS loading dye separated on
$12.5 \%$ SDS-PAGE gel. Detection of protein was done by using anti-Pol $\beta$ monoclonal primary antibody (Novus) by diluting 1:5000 in Phosphate-Buffered Saline (PBS) containing $0.05 \%$ Tween-20 and 5\% nonfat, dry milk. Incubation with secondary antibodies (SC-2020; 1:10,000) and detection reaction were performed according to manufacturer's instruction (PIERCE).

\section{Study of Cytotoxicity}

2.5.1. Alkylating agent (MMS, NMU) and UV sensitivity assay by MTT: HeLa cell and Pol $\beta \Delta_{208-304}$ transfected cells are plated in 96 well plates. After 12-24 hrs cell medium was discarded. Cells were treated with alkylating agent (NMU, MMS) of different concentrations. Then after $24 \mathrm{hrs} 5 \mathrm{mg} / \mathrm{ml}$ concentration of MTT (dissolved in PBS) were added in each well. After 4 hours MTT was removed from each well and $100 \mu \mathrm{l}$ DMSO was added in each well. Absorbency was measured in $540 \mathrm{~nm}$ (Hermann et al., 1994; Hirsh et al., 2009). The sensitivity of Pol $\beta \Delta_{208-304}$ in chemical treatment was detected by calculating rate of survival using following formula: inhibition rate $(\%)=(1-$ OD A1/A0) x100. Here A1 is absorbency of treated cells, and A0 is absorbency of control cell without treatment. Cell plated in above mentioned protocol and treated after $24 \mathrm{hrs}$ with MMS different doses in Serum free medium. All the assays were done in triplicate.

\section{$\mathrm{H}_{2} \mathrm{O}_{2}$, UV sensitivity detection by MTT assay}

Cell survivability was analyzed using a 3-(4,5-dimethylthiazol-2-yl)-2,5 diphenyltetrazolium bromide (MTT) assay (Sigma, MO, USA) after treatment with H202, UV (Krahn et al., 2004). HeLa cells and Pol $\beta \Delta_{208-304}$ transfected cells were plated onto 96 well plates (1500/well) and after $24 \mathrm{hrs}$ medium was discarded and serum free medium was added before 1 $\mathrm{hr}$ of treatment. $\mathrm{H}_{2} \mathrm{O}_{2}$ of different concentrations $(12 \mu \mathrm{M}$ $-1000 \mu \mathrm{M}$ ) was added, medium was discarded after 1 hour and new medium added after 12 and half hours cells treated with $10 \mu \mathrm{l}$ MTT dissolved in PBS. After 3 and half hours, MTT was removed from each well and $100 \mu \mathrm{l}$ DMSO was added to each well.

For UV radiation experiment, cells were exposed to different doses of UV light (Stratagene UV-C bulbs, 254 $\mathrm{nm}$ ) at a dose in between $5-50 \mathrm{~J} / \mathrm{m}^{2}$. Then $100 \mu \mathrm{l}$ of serum free medium was added to each well. After 22 hours of treatment, $10 \mu \mathrm{l}$ MTT (dissolved in PBS) was added with a final concentration of $0.5 \mathrm{mg} / \mathrm{ml}$. After 4 hours, medium was removed from each well and $100 \mu \mathrm{L}$ DMSO was added to each well. Absorbency measured at $540 \mathrm{nM}$. All the assays were done in triplicate.

\section{Colony forming assay}

Exponentially grown cells were seeded in $35 \mathrm{~mm}$ dishes $(300 / \mathrm{ml})$ and next day treated with UV at 5-15 J/ $\mathrm{m}^{2}$, MMS of $0.125-2 \mu \mathrm{M}$, NMU of $1-100 \mu \mathrm{M}, \mathrm{H}_{2} \mathrm{O}_{2}$ of 0.05 to $2 \mu \mathrm{M}$ concentrations. After treatment, the cells were washed with PBS and fresh medium was added and cultured in complete medium for 2 weeks. After 14 days of incubation, colonies were fixed with ethanol, stained with Giemsa (25\% in ethanol), counted and calculated 
as percent of colony following this formula: Untreated/ controls x100. All the assays were done in triplicate.

\section{Study of apoptosis}

Sensitivity study by DNA fragmentation assay against MMS, NMU, $\mathrm{H}_{2} \mathrm{O}_{2}$, and UV: DNA Pol $\beta \Delta_{208-304}$ cells ( $5 \times 105$ cells) are seeded in $100 \mathrm{~mm}$ dish. To assess the fragmentation of cellular DNA into the characteristic apoptotic ladder, cells were treated with the mutagen (UV, NMU, MMS, and $\mathrm{H}_{2} \mathrm{O}_{2}$ ) of different time $(6,9,12$ h) post treatment incubation. Then cells were harvested by trypsinization and lysed in ice-cold cell lysis buffer (10 mM Tris, pH 7.5; 1 mM EDTA; 0.5\% Triton X-100). Then lysed cells were incubated with $0.1 \%$ SDS and $300 \mathrm{mg} / \mathrm{ml}$ of Proteinase $\mathrm{K}$ at $56^{\circ} \mathrm{C}$ overnight. Aqueous phases were extracted with phenol/chloroform and the DNA samples were precipitated with cold ethanol in the presence of $1 / 2$ volume of $10 \mathrm{M}$ ammonium acetate, dried and dissolved by heating at $55 \mathrm{oC}$ in TE buffer before loading in a gel. DNA subjected to electrophoresis using $1.8 \%$ agarose in Tris-borate buffer. DNA was visualized by staining with ethidium bromide and photographed in gel.

\section{Caspase activation detection}

For caspase 3,9 activation assays, whole cell extracts were made from cells treated with $\mathrm{UV}$ and $\mathrm{H}_{2} \mathrm{O}_{2}$ with either for different time period or concentrations. Cell lysates were prepared by using lysis buffer containing $20 \mathrm{mM}$ Tris$\mathrm{HCl} \mathrm{pH} 8,150 \mathrm{mM} \mathrm{NaCl}, 1 \mathrm{mM}$ of EDTA, $1 \mathrm{mM}$ EGTA and Protease inhibitor (Protease inhibitor mini kit; Roche applied Bioscience). Proteins were electrophoretically separated on $12.5 \%$ gel SDS-PAGE and transferred onto nitrocellulose membrane. The membrane was preincubated in TBST with 5\% blocker (Fat free milk) for 30 mins. Then washed with TBST for 5 mins and incubated in primary antibody of caspase 3 , caspase 9 (Cell signaling cat\#9668, \#9505; dilution 1:1000) for overnight as per manufacturer's instruction. Membrane was rinsed with TBST for $1 \mathrm{hr}$ by changing TBST 4-5 times and incubated afterwards with HRP conjugated secondary antibody with $2.5 \%$ blocker (Bio-Rad; cat\#170-6516, Caspase3-Goat anti-mouse IgG; 1:1000; Cell signaling, cat \#7074; HRP conjugate anti rabbit antibody 1:1000 conc.) for $1 \mathrm{hr}$. After washing with TBST, bands were visualized by using Super Signal west pico (Pierce, IL).

\section{Statistical analysis}

Data were presented as mean \pm standard deviation (SD). Analysis of variance (ANOVA) followed by Bonferroni's test was used to determine the significant differences between groups. Values of P less than 0.05 were considered significant.

\section{Results}

\section{Western blot analysis to detect expression of truncated} product

PCR products were cloned in pcDNAIneo vector (Figure 1.a). Presence of a variant was confirmed by digestion with restriction enzyme (Fig1.b). The variant clones were transfected into HeLa cell and the stable cell lines were generated. The expression of the variant product was confirmed by RT-PCR (Figure 1.c) and western blot analysis (Figure 1.d). For further analyses,

\section{Alkylating agent sensitivity detection by MTT assay}

Cytotoxicity of Pol $\beta \Delta_{208-304}$ cells were determined and compared with the control HeLa cells and HeLa transfected with vector alone (data not shown) by the MTT assay. Cell cytotoxicity assay indicate that transfected cell are more sensitive to NMU and MMS than control cell line.

Treatment of Pol $\beta \Delta_{208-304}$ cells and control cells with MMS $(1 \mu \mathrm{M}-750 \mu \mathrm{M})$ results in the decrease of the percentage of cell survival. Treatment of this cell lines with $10 \mu \mathrm{M}$ MMS resulted in the $89 \%$ cell survival compared to $94 \%$ cell survival noticed in HeLa control cells. In $250 \mu \mathrm{M}$ doses of MMS, $41 \%$ control cells are dead when same concentration of MMS, resulted in $70 \%$ of cell death in transfected cell line. These results showed that the Pol $\beta \Delta_{208-304}$ cells were more sensitive to MMS treatment than parental HeLa cell line (Figure 2.a). Similar trend were observed when $\operatorname{Pol} \beta \Delta_{208-304}$ cells were treated with NMU (1-500 $\mu \mathrm{M})$ (Figure 2.a). The results show that almost $50 \%$ HeLa cells died after treatment with $250 \mu \mathrm{M}$ NMU (Figure 2.b) in control cell whereas $89 \%$ Pol $\beta \Delta_{208-304}$ transfected cells died at the same concentration of NMU. Treatment resulted in the death of $21 \%, 33 \%, 51 \%$, and $75 \%$ of cell death at concentrations of $50 \mu \mathrm{M}, 100 \mu \mathrm{M}$, and $250 \mu \mathrm{M}, 500 \mathrm{uM}$ respectively in HeLa cells where $\operatorname{Pol} \beta \Delta_{208-304}$ exhibited $34 \%, 65 \%, 91 \%, 98 \%$ of cell death at the same concentrations of NMU. These data indicated that Pol $\beta \Delta_{208-304}$ could increase the sensitivity towards NMU and MMS at a significant level.

a.

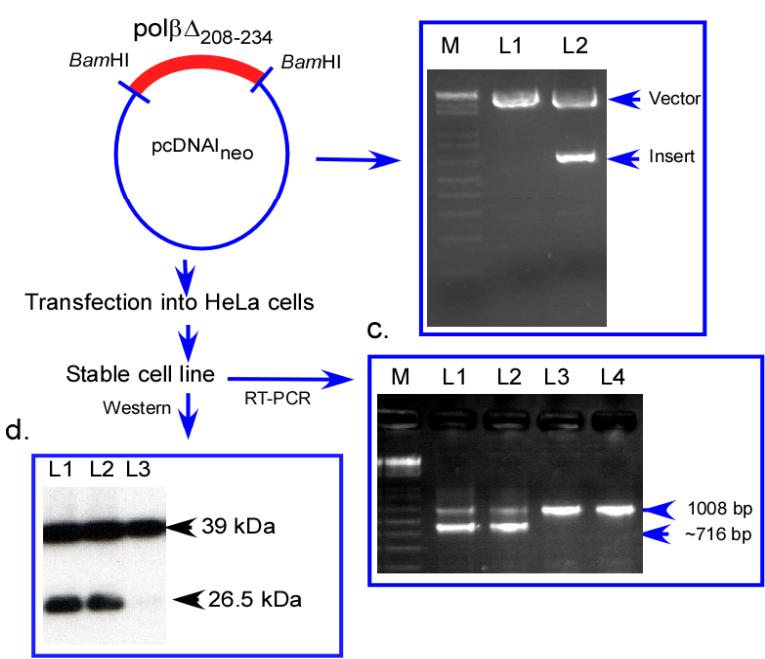

Figure 1. a Schematic Construction of recombinant plasmid inserted with Pol $\beta \Delta_{208-304}$. b Cloning of $\operatorname{Pol} \beta \Delta_{208-304}$ in vector. M; Marker, L1; vector without insert, L2; vector with insert of $716 \mathrm{bp}$. c RT-PCR product of Pol $\beta \Delta_{208-304}$ transfected cell line and normal cell line and vector alone. M; Marker, L1 and L2: RT product of Pol $\beta \Delta_{208-304}$ transfected cell line 1 and cell line ; L3: RT-PCR product of control cell line and L4: Hela cell transfected with vector alone. d Detection of Expression of DNA pol $\beta$ by western blot analysis. L1and L2: $\operatorname{Pol} \beta \Delta_{208-304}$ transfected cell line 1 and 2 respectively.L3: Hela cell line without transfection 
$\mathrm{H}_{2} \mathrm{O}_{2}, \mathrm{UV}$ sensitivity assay by $\mathrm{MTT}$

$\operatorname{Pol} \beta \Delta_{208-304}$ transfected cells are treated with oxidative stress producing agent $\mathrm{H}_{2} \mathrm{O}_{2}$ of different concentrations and radiating agent $\mathrm{UV}$ at different doses. When $\operatorname{Pol} \beta \Delta_{208-304}$ cells were treated with $\mathrm{H}_{2} \mathrm{O}_{2}$ of different concentrations (0.01-1mM), almost $50 \%$ cell died in control cells after treatment with $0.5 \mathrm{mM} \mathrm{H}_{2} \mathrm{O}_{2}$ for $6 \mathrm{hrs}$ whereas cell death rate is much higher $(66 \%)$ in $\operatorname{Pol} \beta \Delta_{208-304}$. cell line.

a.

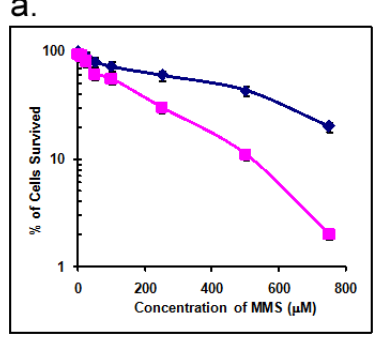

C.

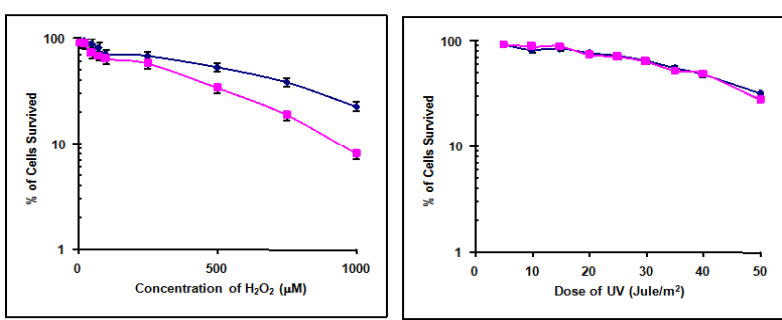

Figure 2. a \& b Effects of Carcinogen on Cell Viability were Examined by Using the MTT (thiazolyl blue) assay. This assay monitors conversion of MTT to insoluble purple formazan in a reaction catalyzed by mitochondrial dehydrogenases in viable cells. - $\boldsymbol{\Delta}$ - denotes HeLa cells, whereas - - indicates HeLapol $\beta \Delta$ cells. a; Graphically represent Cell viability along with treatment of MMS of different concentration. b; Cell viability with different concentration of NMU. c; Cell viability with different concentration of $\mathrm{H} 2 \mathrm{O} 2$, d; Cell viability with different concentration of UV. The data represent mean \pm SD $(\mathrm{n}=3)$

A)

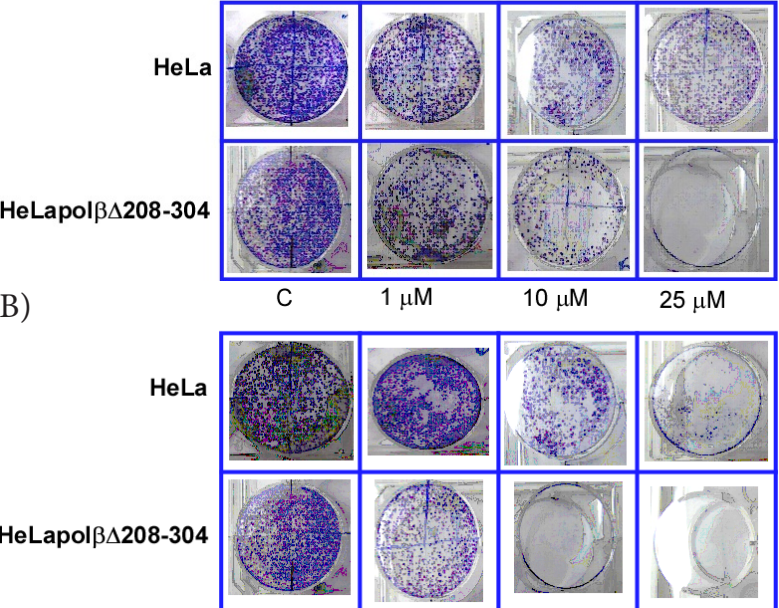

Figure 3. Colony Forming Assay by Treatment of MMS in HeLa Control (Upper) and Pol $\beta \Delta 208-304$ (Lower) Transfected Cell Line. Here $\mathrm{C}$ indicates-control cell line, and $0.120 .25 \mu \mathrm{M}, 0.5 \mu \mathrm{M}$ are concentration of MMS treated in cultured dishes. b. Colony forming assay by treatment with NMU $\mathrm{C}$ indicate Control cell line and $1 \mu \mathrm{M}, 10 \mu \mathrm{M}, 25 \mu \mathrm{M}$ were treated dish by different concentration of NMU respectively
Treatment resulted in the death of $6,29,80 \%$ cells at concentrations of $10 \mu \mathrm{M}, 100 \mu \mathrm{M}$ and $750 \mu \mathrm{M}$ whereas the Pol $\beta \Delta_{208-304}$ exhibited 9, 36, $84 \%$ cell death at the same concentrations of $\mathrm{H}_{2} \mathrm{O}_{2}$ (Figure 2.c)

Treatment of Pol $\beta \Delta_{208-304}$ cells with UV of 5-50 J/ $\mathrm{m}^{2}$ resulted same sensitivity for both control cells and Pol $\beta \Delta_{208-304}$ transfected cells. Treatment of this cell line with UV resulted $94 \%, 89 \%, 84 \%, 74 \%, 71 \%$ cell survival, where in HeLa cell 93\%, 83\%,85\%,77\%,73\% cells are survived in $5-25 \mathrm{~J} / \mathrm{m}^{2}$ irradiation indicate that sensitivity are almost same. (Figure $2 \mathrm{~d}$ )

Colony forming assay by treating with alkylating agent ( $M M S, N M U), \mathrm{H}_{2} \mathrm{O}_{2}, U V$

Results of colony forming assay indicate that transfected cells are more sensitive to MMS, NMU, $\mathrm{H}_{2} \mathrm{O}_{2}$ than HeLa cell line or HeLa cells transfected with vector DNA alone (Figure $3 \mathrm{a} \& \mathrm{~b}$ andFigure $4 \mathrm{a}, \mathrm{b}, \mathrm{c}, \mathrm{d}$ ). On the other hand, UV does not affect the transfected cells when compared with HeLa alone (Figure 4 b).

\section{Study of apoptosis}

Sensitivity study by DNA fragmentation assay against MMS, NMU, $\mathrm{H}_{2} \mathrm{O}_{2}$, and UV: After treatment with toxic agent, DNA fragmentation was detected as small bands in a laddering pattern in $1.8 \%$ agarose gel. The results show that in NMU $(100 \mu \mathrm{M})$ and MMS $(250 \mu \mathrm{M})$ treatment the DNA fragmentation is prominent in $6 \mathrm{hrs}$ in $\operatorname{Pol} \beta \Delta_{208-304}$ cells whereas the fragmentation was detected in $9 \mathrm{hrs}$ in treated HeLa cells. In higher doses of chemical treatment transfected cells are showing more degradation of DNA. a.

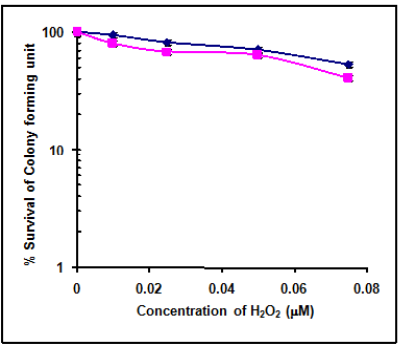

C.

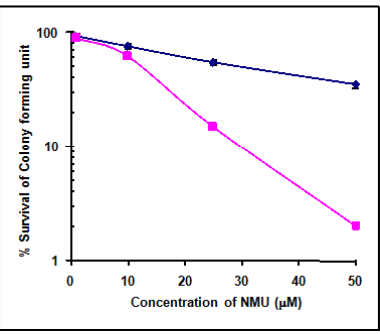

b.

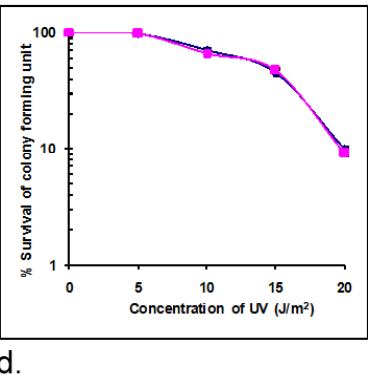

d.

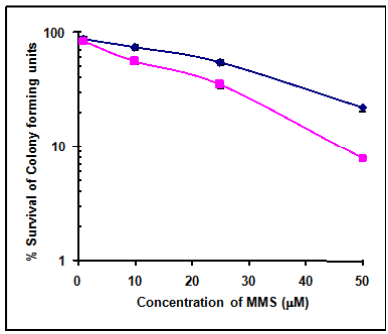

Figure 4. a \&b Graphical representation of colony forming assay. Effect of H202 and UV on the colony forming assay of $\mathrm{HeLa}$ and Hela -pol $\beta \Delta$ cell. $-\boldsymbol{\Delta}$ - denotes HeLa cells, whereas - - indicates HeLapol $\beta \Delta$ cells. a. Shows percentage of colony formation after treatment with different concentrations of $\mathrm{H} 2 \mathrm{O} 2$ b. Graphical presentation of percentage of colony formation after treatment with different doses of UV.c \& d Effect of MMS and $\mathrm{NMU}$ on the colony forming assay of HeLa pol $\beta \Delta$. c Shows percentage of survived colony forming units after treatment with different concentrations of NMU. d. Graphical presentation of percentage of survived colony forming units after treatment with different doses of MMS. The data represent mean $\pm S D(n=3)$. 


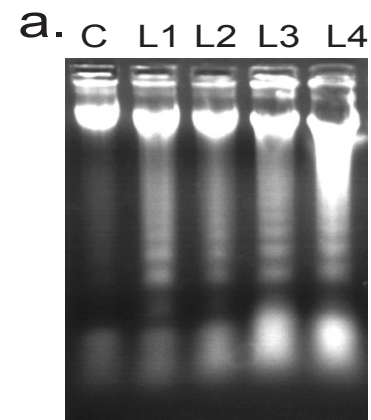

a. C L1 L2 L3 L4

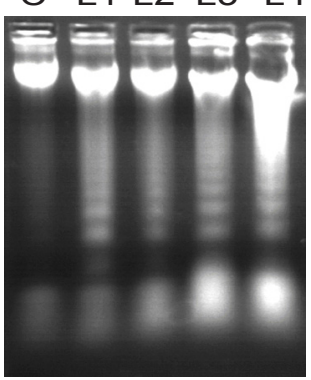

b

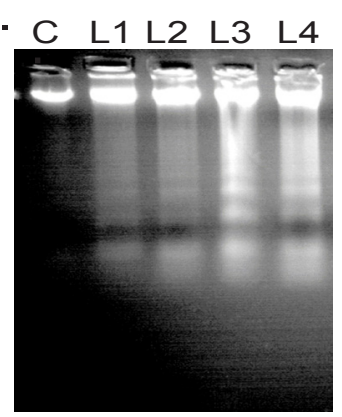

b.

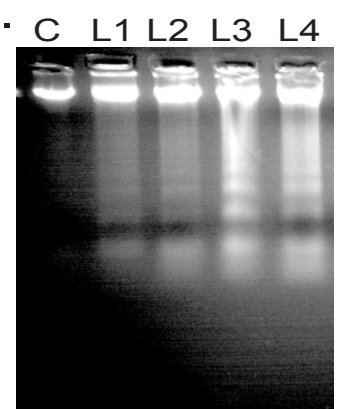

e.

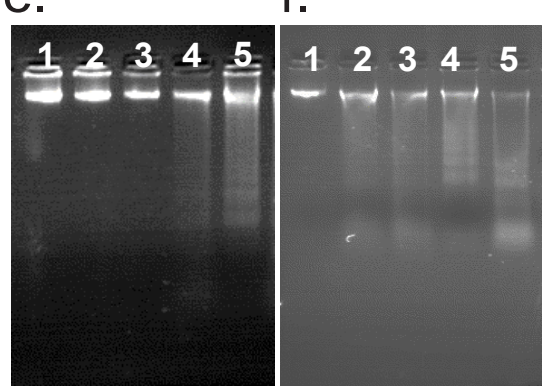

g.

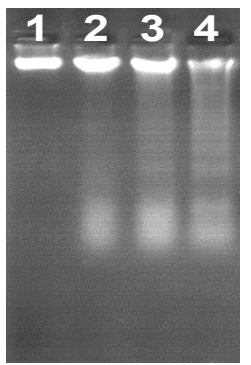

h.

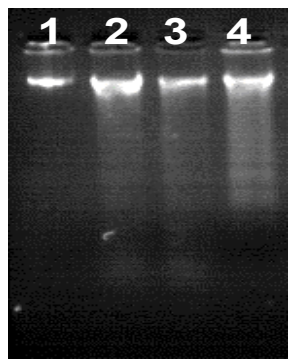

Figure 5. a\&b: Study of Apoptosis by DNA Fragmentation after Treating with $\mathbf{U V}\left(\mathbf{1 0} \mathbf{J} / \mathbf{m}^{2}\right)$. a; DNA laddering after treatment with UV in HeLa cell line b; DNA laddering after treatment with UV in pol $\beta \Delta 208-304$ cell line respectively. In this figure, C indicates control, L1indicate UV treatment after $6 \mathrm{hrs,} \mathrm{L2} \mathrm{indicate} \mathrm{UV} \mathrm{treatment} \mathrm{after} 9 \mathrm{hrs,} \mathrm{L3} \mathrm{indicate} \mathrm{UV} \mathrm{treatment}$ after $12 \mathrm{hrs}$, L4indicate UV treatment after $24 \mathrm{hrs}$. c \&d: Study of apoptosis by DNA laddering after treatment with NMU $(100 \mu \mathrm{M})$. c; the DNA laddering after treatment with doses of NMU in HeLa cell line d; DNA laddering after treatment with NMU in pol $\beta \Delta 208$-304 cell line respectively. C indicate Control, L1 indicate NMU treatment after $6 \mathrm{hrs,} \mathrm{L2} \mathrm{indicate} \mathrm{NMU} \mathrm{treatment} \mathrm{after}$ 9hrs, L3 indicate NMU treatment after 12hrs, L4 indicate NMU treatment after 24hrs. e \&f: DNA laddering showing after treatment with MMS $(250 \mu \mathrm{M})$. e; the DNA laddering after treatment with doses of MMS in HeLa cell line h; DNA laddering after treatment with MMS in pol $\beta \Delta 208$-304 cell line respectively. 1 indicates control; 2 indicate MMS treatment after 3 hrs; 3 indicate MMS treatment after 6hrs; 4 indicate MMS treatment after 9hrs; 5 indicate MMS treatment after $12 \mathrm{hrs}$. $\mathrm{g} \& \mathrm{~h}$ Study of apoptosis by DNA fragmentation assay g; the DNA laddering after treatment with different doses of $\mathrm{H}_{2} \mathrm{O}_{2}$ in HeLa cell line h; DNA laddering after treatment with $\mathrm{H}_{2} \mathrm{O}_{2}$ in pol $\beta \Delta 208-304$ cell line respectively. C indicate control, L1 indicate treatment of $25 \mu \mathrm{M} \mathrm{H}_{2} \mathrm{O}_{2}, \mathrm{~L} 2$ indicate $50 \mu \mathrm{M} \mathrm{H}_{2} \mathrm{O}_{2}$, L3 indicate $100 \mu \mathrm{M} \mathrm{H}_{2} \mathrm{O}_{2}$

A.

\section{Caspase 3}

HeLa-MMS Treatment $(100 \mu \mathrm{M})$ c $6 r^{r_{s}} n^{r^{s}}{ }^{2} r_{2}^{k^{s}} n^{s}$

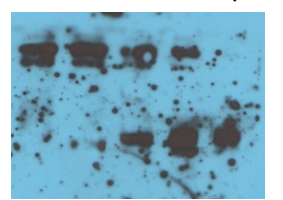

HeLapol $\beta \Delta$-MMS Treatment $(100 \mu \mathrm{M})$

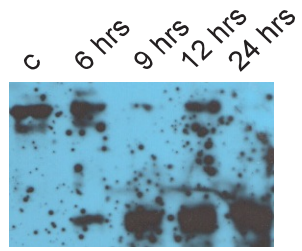

B.

Caspase 9

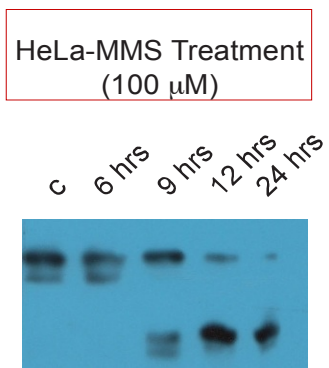

HeLapol $\beta \Delta$-MMS Treatment $(100 \mu \mathrm{M})$
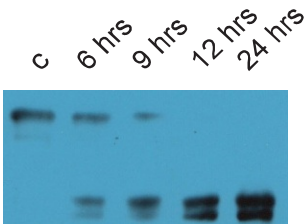

C.

Caspase 3

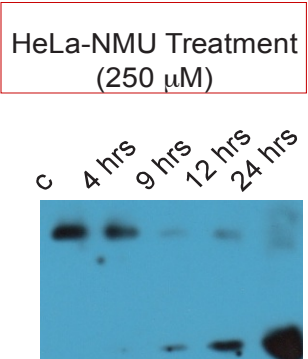

HeLapol $\beta \Delta$-NMU Treatment $(250 \mu \mathrm{M})$
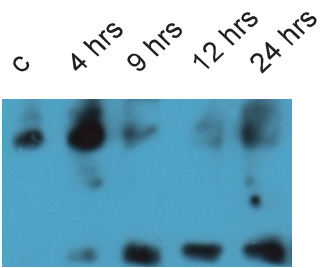

D.

\section{Caspase 9}
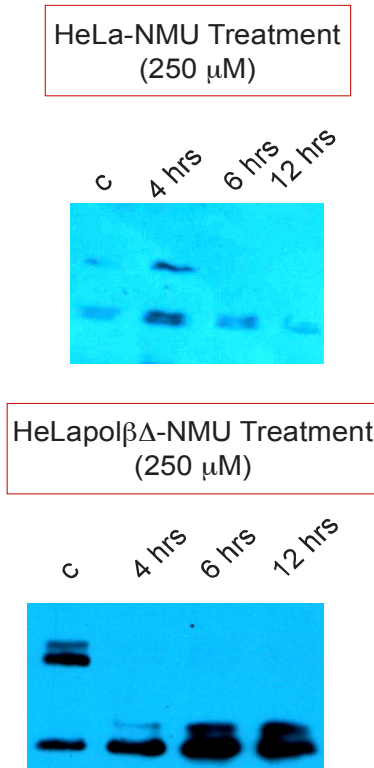

Figure 6. Study of Apoptosis by Caspase assay Detected by Western blot Analysis in HeLa Cell Line and

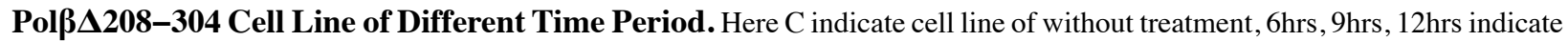
cell line with treatment after $6 \mathrm{hrs}, 9 \mathrm{hrs}, 12 \mathrm{hrs}$ respectively. A: caspase 3 activation by treatment with MMS (100 $\mu \mathrm{M})$. B. Caspase 9 activation by MMS $(100 \mu \mathrm{M})$ treatment. C: Caspase 3 activation by NMU $(250 \mu \mathrm{M})$ treatment. D: Caspase 9 activation by NMU $(250 \mu \mathrm{M})$ treatment 
Caspase 3

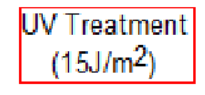

C $6 \begin{array}{lll}6 & 9 & 12\end{array}$

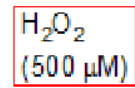

$6 \quad 9 \quad 12$
HeLa
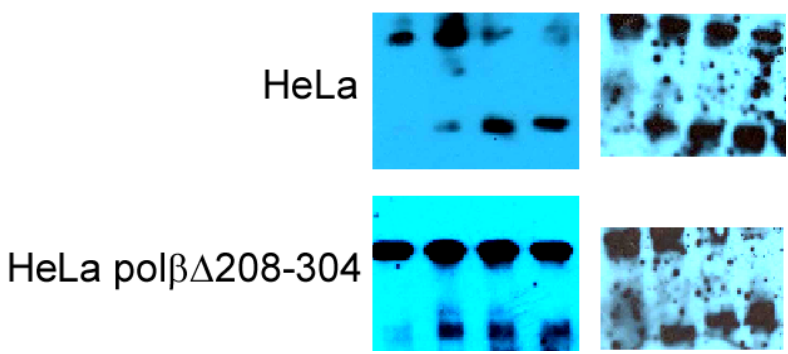

Figure 7. Caspase 3 Activation Detection by UV and $\mathrm{H}_{2} \mathrm{O}_{2}$ Treatment. $\mathrm{C}$ indicate control cell line 6,9,12 indicate $6 \mathrm{hrs}, 9 \mathrm{hrs}, 12 \mathrm{hrs}$ respectively of $\mathrm{UV}\left(15 \mathrm{~J} / \mathrm{m}^{2}\right)$ and $\mathrm{H}_{2} \mathrm{O}_{2}$ treatment

Cells are more sensitive to NMU than MMS (Figure 5,c ,d, $\mathrm{e}, \mathrm{f})$. In case of UV treatment, at the dose of $10 \mathrm{~J} / \mathrm{m}^{2}$, the DNA laddering was prominent in Pol $\beta \Delta_{208-304}$ cells (Figure $5 . \mathrm{a}, \mathrm{b})$ as well as in HeLa control indicate that pol $\beta \Delta$ transfected cells are equally sensitive to UV like control cells. DNA fragmentation assay indicate that $\operatorname{Pol} \beta \Delta_{208-304}$ cells are more sensitive to NMU and MMS than UV. HeLa and $\operatorname{Pol} \beta \Delta_{208-304}$ cells were treated with different concentrations of $25 \mu \mathrm{M}-100 \mu \mathrm{M}$ of $\mathrm{H}_{2} \mathrm{O}_{2}$ indicate that pol $\beta \Delta$ are little more sensitive to $\mathrm{H}_{2} \mathrm{O}_{2}$ (Figure $5 \mathrm{~g} \& \mathrm{~h}$ ).

\section{Caspase activation detection}

To gain further insight into whether caspases are involved in alkylating agent mediated apoptotic signals, we determined the activation of caspase- 9 and -3 in HeLa and Pol $\beta \Delta_{208-304}$ cells. Binding of cytochrome $\mathrm{C}$ to Apaf-1 results in the cleavage of procaspase-9, which in turn activates caspase-3. In order to determine whether caspases are activated we measured the changes in caspases-9 and -3 activity in HeLa and $\operatorname{Pol} \beta \Delta_{208-304}$ cells after treatment.

In this study we noticed that after $6 \mathrm{hrs}$ of treatment with NMU and MMS treatment Pol $\beta \Delta_{208-304}$ transfected cell activation started where no activation is observed in control cell line (Figure 6A, B, C, D). In the present study we also noticed $\mathrm{UV}$ and $\mathrm{H}_{2} \mathrm{O}_{2}$ induced activation of caspase- 3 in both HeLa and pol $\beta \Delta$ cells, but the activation rate is same in Pol $\beta \Delta_{208-304}$ cells compared to HeLa cells (Figure 7). As shown in Figure 7, the activation of caspase 3 occurred at the dose of $15 \mathrm{~J} / \mathrm{m}^{2}$ in HeLa cell, whereas the same activation was detected in $\operatorname{Pol} \beta \Delta_{208-304}$ cells at same dose.

Caspase 3 are activated at $6 \mathrm{hrs}$ of UV treatment in case of HeLa control and $\operatorname{Pol} \beta \Delta_{208-304}$ cell line indicate this cell line is sensitive to UV treatment but not due to transfection of pol $\beta \Delta$, the activation occurs as early as 6 hrs. Therefore this result suggests that $\operatorname{Pol} \beta \Delta_{208-304}$ are not sensitive to UV treatment. In case of $\mathrm{H}_{2} \mathrm{O}_{2}$ after $6 \mathrm{hrs}$ of $\left(500 \mu \mathrm{M} \mathrm{H}_{2} \mathrm{O}_{2}\right)$ treatment caspase activation occurs in control and transfected cell line.

\section{Discussion}

$\operatorname{Pol} \beta \Delta_{208-304}$ variant has large deletion of 97 amino acids in the catalytic part of amino acids residues 208 to 304. The variant of $716 \mathrm{bp}$ has deletion in Exon 11-13. The exon 11 has nucleotidyl selection activity; exons 12 and 13 have dNTPs selection activity (Idris et al., 2006). Hence deletion of this part may affect polymerizing activity but single strand binding and double strand binding activity presumed to be remained same that have nucleotidyl transferase activity and dNTPs selection activity. In this variant of DNA pol $\beta$ one of the three aspartates at position 256 (Asp190, Asp192, and Asp256) necessary for catalysis reaction is missing which is located at exon 12 [24-26] and Amino acids Tyr271, Phe272, Asn 279 and Arg283 located in catalytic domain that have role in minor groove interaction thus maintaining the fidelity of the polymerization are also missing (Dong et al., 2002; Sweasy et al., 2005; Lang et al., 2007). The fidelity of polymerization will also be affected due to deletion of Exon 13. Bhattacharyya and Banerjee (1997) have shown that 87 bp deletion of pol $\beta$ in breast, colon, and lung cancer has a dominant negative (DN) effect (Bhattacharyya and Banerjee 1997). As the alteration is heterozygous, this variant will compete with WT pol $\beta$ for DNA binding, thus may act as dominant negative manner. The hindrance of the function of wild-type pol $\beta$ may sensitize the cancer cells to the alkylating agent and thus may the target of an effective therapy.

The Wild type (WT) pol $\beta$ consists of 335 amino acid residues. The variant form has a deletion of 97 amino acids in catalytic part. The sensitivity of this new cell line, $\operatorname{Pol} \beta \Delta_{208-304}$, was tested by MTT assay after treating cells with alkylating agents and oxidative stress generating agent $\mathrm{UV}, \mathrm{H}_{2} \mathrm{O}_{2}$. Pol $\beta \Delta_{208-304}$ cells exhibit greater sensitivity to alkylating agent and less sensitivity towards $\mathrm{H}_{2} \mathrm{O}_{2}$. Pol $\beta \Delta_{208-304}$ has deletion of exon 11-13. Pol $\beta$-DNA complex binds to the incoming nucleoside triphosphate (dNTP) and place it within the active site. Subsequently, conformational changes occur, the incorrect dNTP binding results in a poor fit, and disrupt DNA repair mechanism. As this newly identified mutant lost dNTPs selection region it may incorporate wrong bases that may results poor fitting or no repair.

It has been shown that Mouse embryonic fibroblast cells deficient in pol $\beta$ are highly sensitive to alkylating agents. The lesions produced by these agents are repaired by BER, thus confirming the role of polb in this repair pathway (Sobol et al., 1996; Ochs et al., 1999). If this variant is a dominant negative one, then it is thought to bind to glycosilase and AP endonuclease treated DNA sites hence may block access of wild type pol $\beta$. If this hypothesis is true, then we may expect an increased sensitivity of pol $\beta \Delta_{208-304}$ variant expressing HeLa cells to alkylating drugs. Significant increase in alkylating drug sensitivity was observed in the pol $\beta \Delta$ cells suggesting inhibition of BER (Figure 2,3,4).

The MTT assay results have shown that the pol $\beta \Delta_{208-304}$ cells are more sensitive to MMS as well as NMU (Figure 2.a \&b). In this study, the MMS, NMU treatment 
of pol $\beta \Delta_{208-304}$ cells have showed enhanced DNA fragmentation than that of HeLa cells. DNA laddering of $\operatorname{pol} \beta \Delta_{208-304}$ cells was apparent at lower doses of MMS, NMU (Figure 5).

If we assume that pol $\beta \Delta_{208-304}$ is a dominant negative mutant, then these cells are not expected to be more sensitive to UV irradiation. The nucleotide excision repair (NER) pathway repairs DNA damage resulting from UVC irradiation which produces primarily pyrimidine dimmers. Pol $\beta$ is not involved in this process. No significant difference in UVC sensitivity could be observed between HeLa cells and HeLa pol $\beta \Delta_{208-304}$ cells (Figure 2d, 4b). This data also indicates that the presumed dominant negative mutant of pol $\beta$ does not interfere with NER.

Like ionizing radiation, causes oxidation at abasic sites, purines and pyrimidines, and SSBs occurs by $\mathrm{H}_{2} \mathrm{O}_{2}$ treatment ( $\mathrm{Li}$ et al., 1997). $\mathrm{H}_{2} \mathrm{O}_{2}$-treated pol $\beta$ null and normal cells show no difference between repair of SSBs, indicating pol $\beta$ independent repair of DNA damage (Peus et al., 1999). The oxidized AP sites may not be effectively excised by pol $\beta$ after $\mathrm{H}_{2} \mathrm{O}_{2}$ treatment (Pelle et al., 1990). In our study, pol $\beta \Delta 208-304$ cells are showing same sensitivity as that of the HeLa control cell line. Therefore, the data also indicates that radiation and $\mathrm{H}_{2} \mathrm{O}_{2}$ induced damage is being repaired by pol $\beta$-independent long patch repair pathway.

As this variant has its 8-kDa ss DNA binding domain is intact, it will bind to the SSBs and the 5'-deoxyribose phosphate will be removed by the dRP lyase activity of pol $\beta$. But as the catalytic domain is not intact, the sealing of the abasic site may not be possible. Therefore SSBs will be accumulated that may trigger of cell death particularly apoptosis. Therefore, we measured the mitochondrial damage related caspases such as caspase 9 and caspase 3. In addition, as the activation of caspase 9 and caspase 3 activity leads to PARP degradation, we have compared the PARP degradation pattern in these two cell lines. The first step for the reactive oxygen species (ROS) mediated apoptosis is that cytochrome $\mathrm{c}$ binds to Apaf thus forming a complex called apoptosome which recruits and activates procaspase 9 Then caspase 9 cleaves inactive procaspase 3 to form active caspase 3 . We thus examined the effects of MMS, NMU, $\mathrm{H}_{2} \mathrm{O}_{2}$ and UV on the processing of caspase 9 and caspase 3 , which are directly activated by caspase 9 (Hussain et al., 1995; Lawley et al., 2000). The results of caspase assay also indicate more activation of caspases in pol $\beta \Delta_{208-304}$ transfected cell line.

In conclusion, we have identified a variant form of $\operatorname{pol} \beta$, which is specific for ovarian cancer, has a potential to be a dominant negative mutant. This presumed to be pol $\beta$ DN mutant, has intact $\mathrm{N}$-terminal DNA binding domain may be disrupting the function of the WT pol $\beta$ by binding to the specific damaged DNA (AP sites). As this DN mutant lost it's catalytic domain partially thereby lost the catalytic ability. In addition, when this DN mutant binds to the gap it may also hinder the binding of other DNA polymerases. Hence it may inhibit both SP BER and LP BER. Similar observation was made (Clairmont and Sweasy, 1996; Clairmont et al., 1998) where a pol $\beta$ mutant containing yeast cells are sensitive to alkylating agent but not to UV indicating an involvement in BER but not in NER. Another study by Bhattacharyya and Banerjee showed an heterozygous variant form without catalytic domain exhibited substantially decreased BER activity and increased sensitivity to MNNG (Bhattacharyya and Banerjee, 1997). The alkylated DNA is not exclusively repaired by the BER pathway but mismatch repair is also involved in the removal of damage resulting from alkylating agents (deWind et al., 1999). But in this case the pol $\beta \Delta_{208-304}$ construct also blocks this escape route.

The activation of caspase 9 became apparent and progressed at least up to 6 hours (Figure 7) after alkylating agent treatment in $\operatorname{pol} \beta \Delta_{208-304}$ than control cell line. pol $\beta \Delta_{208-304}$ transfected cells susceptible to chemotherapeutic agent like alkylating agent. This would represent a clinical significance if translated into clinical setting because resistance to radiation or chemo during the relapse of the disease could be potentially overcome by this approach. Hence hopefully in the near future, strategies based on RNAi will be ready for preclinical or clinical trials.

\section{Acknowledgements}

The work was supported by the Department of Biotechnology, Government of India (No. BT/PR851/ BRB/10/942/2011) and by the West Bengal Department of Biotechnology, Govt, of West Bengal [No. 559-BT (Estt)/RD-1/11 Dated 12-08-2013]. We also like to thank Sibasis Jana for editorial assistance.

\section{References}

Beard WA, Wilson SH (2000). Structural design of a eukaryotic DNA repair polymerase: DNA polymerase beta. Mutat Res, 460, 231-44.

Beard WA, Wilson SH (2006). Structure and mechanism of DNA polymerase Beta. Chem Rev, 106, 361-82.

Bhattacharyya N, Banerjee S (1997). A variant of DNA polymerase beta acts as a dominant negative mutant. PNAS, 94, 10324-9.

Bhattacharyya N, Banerjee S (2000). A novel role of XRCC1 in the functions of a DNA polymerase beta variant. Biochemistry, 40, 9005-13.

Bhattacharyya N, Banerjee T, Patel U, Banerjee S (2001). Impaired repair activity of a truncated DNA polymerase beta protein. Life Sciences, 69, 271-80.

Bhattacharyya N, Chen HC, Comhair S, Erzurum SC, Banerjee $\mathrm{S}$ (1999a).Variant forms of DNA polymerase beta in primary lung carcinomas. DNA Cell Biol, 18, 549-54.

Bhattacharyya N, Chen HC, Grundfest SB, Banerjee S (1999b). Alteration of $\mathrm{hMSH} 2$ and DNA polymerase $b$ genes in breast carcinomas and fibroadenomas. BiocheBiophys Res Comm, 259, 429-35.

Chen HC, Bhattacharyya N, Wang L, Banerjee S (2002). Heterogeneity in expression and functional analysis of DNA polymerase b in human tumor cell lines. Gene Expression, 10, 115-23.

Chen HC, Bhattacharyya N, Wang L, et al (2000). Defective DNA repair genes in a primary culture of human renal cell carcinoma. Cancer Res Clinic Oncol, 126, 185-90.

Clairmont CA, Sweasy JB (1996). Dominant negative rat DNA polymerase beta mutants interfere with base excision repair in Saccharomyces cerevisiae. J Bacteriol, 178, 656-61.

Clairmont CA, Sweasy JB (1998). The Pol beta-14 dominant 
HeLa Cells Containing a Truncated Form of DNA Polymerase beta are Sensitized to Alkylating Agents

negative rat DNA polymerase beta mutator mutant commits errors during the gap-filling step of base excision repair in Saccharomyces cerevisiae. J Bacteriol ,180, 2292-7.

Dalal S, Chikova A, Jaeger J, Sweasy JB (2008). The Leu22Pro tumor-associated variant of DNA polymerase beta is dRPlyase deficient. Nucleic Acids Research, 36, 411-22.

Dalal S, Hile S, Eckert KA, Sun KW, Starcevic D, Sweasy JB (2005). Prostate-cancer-associated I260M variant of DNA polymerase $\beta$ is a sequence-specific mutator. Biochemistry, 44, 15664-73.

Dalal S, Kosa JL, and Sweasy JB (2004). The D246V Mutant of DNA Polymerase beta Misincorporates Nucleotides. The Journal of Biological Chemistry, 279, 577-84.

de Wind N, Dekker M, Claij N, et al (1999). HNPCC-like cancer predisposition in mice through simultaneous loss of Msh3 and Msh6 mismatch-repair protein functions H. Nature Genet, 23, 359-62.

Dobashi Y, Shuin T, Tsuruga H, Uemura H, Torigoe S, Kubota Y (1994). DNA polymerase $\beta$ gene mutation in human prostate cancer. Cancer Research, 54, 2827-9.

Dong Z, Zhao G, Zhao Q, et al (2002). A study of DNA polymerase beta mutation in human esophageal cancer. Zhonghua Yi XueZaZhi, 82, 899-902.

Douki T, Reynaud-AngelinA, Cadet J, Sage E (2003). Bipyrimidine photoproducts rather than oxidative lesions are the main type of DNA damage involved in the genotoxic effect of solar UVA radiation. Biochemistry, 42, 9221-8.

Fortini P, Pascucci B, Parlanti E, et al (2003). The base excision repair: mechanisms and its relevance for cancer susceptibility. Biochemie, 85, 1053-71.

Friedberg EC (2003). DNA damage and repair. Nature, 421, 436-440.

Gu A, Ji G, Zhu P, et al (2010). Nucleotide excision repair polymorphisms, polycyclic aromatic hydrocarbon exposure, and their effects on sperm deoxyribonucleic acid damage and male factor infertility. Fertility and Sterility, 94, 2620-5.

Herrmann M, Lorenz HM, Voll R, et al (1994). A rapid and simple method for the isolation of apoptotic DNA fragmentation. Nucleic acids research, 22, 5506-7.

Hirsch HA, Iliopoulos D, TsichlisPN, StruhlK (2009). Metformin selectively targets cancer stem cells, and acts together with chemotherapy to block tumor growth and prolong remission. Cancer Res, 69, 7507-11.

Hoffmann D, Hecht SS (1985). Nicotine-derived N-nitrosamines and tobaccorelated cancer: current status and future directions. Cancer Res, 45, 935-44.

Husain I, Morton BS, Beard WA, et al (1995). Specific inhibition of DNA polymerase $\beta$ by its $14 \mathrm{kDa}$ domain: role of single- and double-stranded DNA binding and 5'-phosphate recognition. Nucl. Acids Res, 23, 1597-603.

Idris H, Al-Assar O,Wilson SH (2002). DNA polymerase $\beta$. The International Journal of Biochemistry \& Cell Biology, 34, 321-4.

IwanagaA, OuchidaM, MiyazakiK, HoriK, Mukai T (1999). Functional mutation of DNA polymerase $\beta$ found in human gastric cancer - inability of the base excision repair in vitro. Mutant Res, 435, 121-8.

Khanra K, Bhattacharya C, Bhattacharyya N (2012a). Association of a newly identified variant of DNA polymerase beta $\left(\operatorname{pol} \beta \Delta_{63-123,208-304}\right)$ with the risk factor of ovarian carcinoma patients from India. Asian Pacific J Cancer Prev, 13, 1999-2002.

Khanra K, Panda K, Bhattacharya C, et al (2012b). Association between newly identified variant form of DNA polymerase beta $\Delta_{208-305}$ and ovarian cancer. Cancer Biomarkers, 11, $155-60$.

Khanra K, Panda K, Bhattacharya C, et al (2012c). Association of two polymorphisms of DNA polymerase beta in Exon-9 and Exon 11 with ovarian carcinoma patients from India. Asian Pac J Cancer Prev, 13, 1321-4.

Khanra K, Panda K, Mitra AK, et al (2012d). Exon 8-9 mutation of DNA polymerase $\beta$ in ovarian carcinoma patients from Haldia, India. Asian Pacific J Cancer Prev, 13, 4183-6.

Kong X, Mohanty SK, Stephens J, et al (2009). Comparative analysis of different laser systems to study cellular responses to DNA damage in mammalian cells. Nucleic Acids Research, 37, 68 .

Kosa JL, Sweasy JB (1999a). 3-Azido-3-deoxythymidineresistant Mutants of DNA Polymerase $\beta$ Identified by in Vivo Selection. J BiolChem, 274, 3851-8.

Kosa JL, Sweasy JB (1999b). The E249K nutator nutant of DNA Polymerase $\beta$ Extends mispaired termini. The Journal of Biological Chemistry, 10, 35866-72.

Krahn JM, Beard WA, Wilson SH (2004). Structural insights into DNA polymerase $\beta$ deterrents for misincorporation support an induced-fit mechanism for fidelity. Structure, 12, 1823-32.

Lang T, Dalal S, Chikova A, DiMaio D, Sweasy JB (2007). The E295K DNA polymerase beta gastric cancer-associated variant interferes with base excision repair and induces cellular transformation. Mol Cell Biol, 27, 5587-5596.

Lang T, Maitra M, Starcevic D, Li SX, Sweasy JB (2004). ADNA polymerase beta mutant from colon cancer cells induces mutations. Proc Natl AcadSci USA, 101, 6074-9.

Lawley W, Dohert A, Denniss S, Chauhan D, Pruijn G, Venrooij DG, Lunec J, Herbert K (2000). Rapid lupus autoantigen relocalization and reactive oxygen species accumulation following ultraviolet irradiation of human keratinocytes. Rheumatology, 39, 253-61.

Li P, Nijhawan D, Budihardjo I, et al (1997). Cytochrome c and dATP dependent formation of Apaf 1/Caspase-9 complex initiate an apoptotic protease cascade. Cell, 91, 479-89.

Lindahl T (1993). Instability and decay of the primary structure of DNA. Nature, 362, 709-15.

Mouret S, Baudouin C, Charveron M, Favier A, Cadet J, Douki $\mathrm{T}$ (2006). Cyclobutane pyrimidine dimers are predominant DNA lesions in whole human skin exposed to UVA radiation. Proc Natl AcadSci, 103,13765-70.

Ochs K, Sobol RW, Wilson SH, Kaina B (1999). Cells deficient in DNA polymerase beta are hypersensitive to alkylating agent-induced apoptosis and chromosomal breakage. Cancer Research, 59, 1544-51.

Ohshima H, Tatemichi M, Sawa T (2003). Chemical basis of inflammation-inducedCarcinogenesis. Arch Biochem Biophys, 417, 3-11.

Pelle E, Maes D, Padulo GA, Kim KM, Smith WP (1990). An in vitro model to test relative antioxidant potential: ultraviolet-induced lipid peroxidation in liposomes. Archives of Biochemistry and Biophysics, 283, 234-240.

Peus D, Vasa RA, Beyerle A, Meves A, Krautmacher C, Pittelkow MR (1999). UVB activates ERK1/2 and p38 signaling pathways via reactive oxygen species in cultured keratinocytes. J Invest Dermatol, 112, 751-6.

Singhal RK, Prasad R, Wilson SH (1995). DNApolymerase $\beta$ conducts the gap-filling step in uracil-initiated base excision repair in a bovine testis nuclear extract. J BiolChem, 270, 949-57.

Slupphaug G, Kavli B, Krokan HE (2003). The interacting pathways for prevention and repair of oxidative DNA damage. Mutation Research, 531, 231-51.

Sobol RW, Horton JK, Kuhn R, Gu H, Singhal RK, Prasad R, Rajewsky K, Wilson SH (1996). Requirement of mammalian DNA polymerase-beta in base excision repair. Nature, $\mathbf{3 7 9}$, 183-6.

Sobol RW, Wilson SH (2001). Mammalian DNA beta- 


\section{Kalyani Khanra et al}

polymerase in base excision repair of alkylation damage. Prog Nucleic Acid Res MolBiol, 68, 57-74.

Starcevic D, Dalal S, Sweasy JB (2004). Is there a link between DNA polymerase beta and cancer? Cell Cycle, 3, 998-1001.

Sweasy JB, Lang T, Starcevic D, Sun K, Lai C, DiMaio D, Dalal S (2005). Expression of DNA polymerase $\beta$ cancerassociated variants in mouse cells results in cellular transformation. PNAS, 102, 14350-5.

Wilson SH, Sobol RW, Beard WA, Horton JK, Prasad R, VandeBerg BJ (2000). DNA polymerase $\beta$ and mammalian base excision repair. Cold Spring HarborSymp Quant Biol, 65, 143-55.

Yamtich J, Sweasy JB (2010). DNA polymerase family X: function, structure, and cellular roles. BiochimBiophysActa, 1804, $1136-50$. 